\title{
PREPARATION, CHARACTERIZATION, AND IN VITRO SKIN PENETRATION OF MORUS ALBA ROOT EXTRACT NANOEMULSION
}

\author{
MAZAYA FADHILA ${ }^{1}$, ABDUL MUN IM ${ }^{1,2}$, MAHDI JUFRI ${ }^{1 *}$ \\ ${ }^{1}$ Department of Herbal Medicine, Faculty of Pharmacy, Universitas Indonesia, Depok 16424, West Java, Indonesia. ${ }^{2}$ Department \\ of Pharmacognosy-Phytochemistry, Faculty of Pharmacy, Universitas Indonesia, Depok 16424, West Java, Indonesia. \\ Email: mahdi.jufri@farmasi.ui.ac.id
}

Received: 27 May 2019, Revised and Accepted: 22 June 2019

ABSTRACT

Objective: White mulberry (Morus alba) root extract has terpenoid, flavonoid, and stilbene compounds. The stilbenes, oxyresveratrol and resveratrol, have antioxidant and antityrosinase activities. Nanocarriers can help active ingredients to be delivered in a more efficient manner. The advantages of nanoemulsion on products include increased penetration, biocompatibility, and low toxicity due to its non-ionic properties and have the ability to combine the properties of lipophilic and hydrophilic active ingredients. The objective of this study was to prepare, characterize, and evaluate the in vitro skin penetration of $M$. alba root extract nanoemulsion.

Methods: The M. alba root extract was prepared by ionic liquid-based microwave-assisted extraction method. Nanoemulsion was optimized and prepared using virgin coconut oil (VCO), Tween 80, and polyethylene glycol 400 (PEG 400) by aqueous phase-titration method to construct pseudoternary phase diagram. M. alba root extract nanoemulsion was characterized for droplet size, viscosity, zeta potential, and physical stability tests for 12 weeks. In vitro skin penetration of oxyresveratrol from nanoemulsion was determined by the Franz diffusion cell and was compared by macroemulsion preparation, then analyzed by high-performance liquid chromatography method.

Results: Based on pseudoternary phase diagram, nanoemulsion of white mulberry root extract contained of $2 \%$ VCO and $18 \%$ mixture of surfactant Tween 80 and PEG 400 (1:1) was chosen. Nanoemulsion has average globule size of $81.61 \mathrm{~nm}$, with polydispersity index 0.22 , and potential zeta $-1.56 \mathrm{mV}$. The cumulative penetration of oxyresveratrol from nanoemulsion was $55.86 \mu \mathrm{g} / \mathrm{cm}^{2}$ with flux of $6.53 \mu \mathrm{g} / \mathrm{cm}^{2} / \mathrm{h}$, while regular emulsion was $32.45 \mu \mathrm{g} / \mathrm{cm}^{2}$ with flux of $3.5501 \mu \mathrm{g} / \mathrm{cm}^{2} / \mathrm{h}$.

Conclusion: Nanoemulsion of white mulberry root extract was penetrated deeper than regular emulsion.

Keywords: Morus alba, Nanoemulsion, Oxyresveratrol, Skin lightning.

(C) 2019 The Authors. Published by Innovare Academic Sciences Pvt Ltd. This is an open access article under the CC BY license (http://creativecommons. org/licenses/by/4. 0/) DOI: http://dx.doi.org/10.22159/ajpcr.2019.v12i8.34313

\section{INTRODUCTION}

The white mulberry (Morus alba) has been used in traditional Chinese medicine to treat inflammatory diseases. White mulberry root extract has been known to contain terpenoids, flavonoids, and stilbene compounds [1], including oxyresveratrol and resveratrol which have antioxidant and antityrosinase activity [2]. In Indonesia, the white mulberry plant is widely cultivated as the main source of silkworm feed. The utilization of this plant is still limited by fruits and leaves only, while the root part which has antityrosinase activity has not been widely developed. At present, in the market, there are many foreign cosmetic preparations use extracts from the white mulberry root as an active substance along with other natural ingredients. While local cosmetic products have not been utilize the potential of this root. However, oxyresveratrol development in cosmetics is still limited because it has low water solubility so the ability to diffuse through the stratum corneum is low. In addition, oxyresveratrol is unstable in aqueous systems, which are susceptible to discoloration and oxidative isomerization, especially when exposed to light [3]. Therefore, the development of appropriate delivery systems is a need to include the maximum amount of oxyresveratrol in the cosmetics and immediately penetrating into the skin.

Emulsions are a scattering of an immiscible fluid into another balanced out by the nearness of surfactant [4]. Emulsions which have bead sizes between 5 and $200 \mathrm{~nm}$ are named as nanoemulsions, ultrafine emulsions, submicron emulsions, translucent emulsions, and miniemulsions [5,6]. Nanoemulsions are dynamically steady yet thermodynamically flimsy frameworks [7]. The nanosize bead can decrease the event of flocculation, sedimentation, and creaming amid capacity [8].

According to Moghassemi and Hadjizadeh (2014), a rational design of skin delivery systems based on nanocarriers can help active ingredients to be delivered in a more efficient manner. The advantages of nanoemulsion on products include increased penetration, biocompatibility, and low toxicity due to its non-ionic properties and have the ability to combine the properties of lipophilic and hydrophilic active ingredients [9]. This study aims to test a preparation of white mulberry root extract nanoemulsion on containing oxyresveratrol as skin lightening.

\section{MATERIALS AND METHODS}

\section{Materials}

M. alba root extract was produced by ionic liquid-based microwaveassisted extraction method as described before by Fadhila, Jufri, and Mun'im, 2018. Chemicals reagent used was ethanol 80\%, oxyresveratrol standard (Shanghai Yuanye Bio-Technology Co., Ltd.), propylene glycol, Tween 80, polyethylene glycol 400 (PEG 400), virgin coconut oil (VCO), methylparaben, and propylparaben.

\section{Instrument}

The instruments were magnetic stirrer, pH-meter type 510 (Eutech), Ostwald viscometer, zetasizer nano ZS (Malvern Instruments Ltd., United Kingdom), Franz diffusion cell, and high-performance liquid chromatography (HPLC) system (LC-20AT, Shimadzu, Kyoto, Japan). 


\section{Methods}

Construction of pseudoternary phase diagram

To make nanoemulsion, oil stage that we pick was VCO, Tween 80 as the surfactant, PEG 400 as cosurfactant, water as the watery stage, and propylene glycol as entrance enhancer. Surfactant and cosurfactant in proportion 1:1 (v/v) were blended as Smix. The pseudoternary stage graph was created by the water titration strategy at room temperature. The oil stage and Smix were blended at various volume proportions from 1:9 to $1: 9(\mathrm{v} / \mathrm{v})$ and, afterward, were dropped by water carefully under delicate fomentation to every blend. The nanoemulsions were seen as a straightforward fluid. In view of the pseudoternary stage outline, the chose measure of oil stage, surfactant, and cosurfactant and the watery period of nanoemulsion were kept on getting ready white mulberry root separate nanoemulsion [10].

\section{Formulation of nanoemulsion containing M. alba root extract}

Incorporation of white mulberry root extract into nanoemulsion was performed by dissolving white mulberry root extract in oily phase and surfactant. White mulberry root extract containing surfactant and cosurfactant was mixed and added by amount of water. The oily phase containing dissolved extract was added by drops. Target content of extract in nanoemulsion was set to be $1 \%$.

\section{Characterization of nanoemulsion}

To decide the normal bead size and drop measure circulation of the nanoemulsion by unique light dispersing technique, Zetasizer Nano (Malvern Instruments, Worcestershire, UK) was utilized. A similar instrument was utilized to decide the bead surface charge (zeta potential) and polydispersity file (polydispersity index [PDI]). The polydispersity record (PDI) is a list that portrays the variety in size [11]. The viscosity of nanoemulsion was determined using Ostwald viscometer. A calibrated digital $\mathrm{pH}$ meter was used to determine $\mathrm{pH}$ for evaluation and stability test in triplicate at room temperature.

\section{Stability studies}

Stability studies on nanoemulsion were performed by first, rotator the sample at $3500 \mathrm{rpm}$ for $30 \mathrm{~min}$, taking the sample for the heating and cooling for 6 cycles. Sample was storage in oven and refrigerator temperatures $\left(40^{\circ} \mathrm{C}\right.$ and $\left.4^{\circ} \mathrm{C}\right)$ for not $<24 \mathrm{~h}$ each temperature; third, keeping the sample at refrigerator temperature $\left(4^{\circ} \mathrm{C}\right)$, room temperature $\left(25^{\circ} \mathrm{C}\right)$, and oven temperature $\left(40^{\circ} \mathrm{C}\right)$. These studies were performed for the period of 3 months. The organoleptic and $\mathrm{pH}$ were determined at every 2 weeks. The concentration of oxyresveratrol was determined at 0 and 3 months.

\section{In vitro skin permeation study}

As skin pervasion study, rodents (200 g) were gotten from the Laboratory Animal Center of Pharmacy Faculty, Universitas Indonesia and approved by Komisi Etik Penelitian Kesehatan Fakultas Kedokteran, Universitas Indonesia, number 379/UN2.FI/ETIK/2018. The rats were sacrificed after abdominal hair was removed and then, the full skin was excised from the abdominal region. At that point, the skin was expelled from subcutaneous tissue and fat, washed with $0.9 \%$ saline, and after that put away at $4^{\circ} \mathrm{C}$ to use inside $24 \mathrm{~h}$.

Franz diffusion cells were utilized to decide in vitro skin penetration with an extracted rodent skins $\left(1.76 \mathrm{~cm}^{2}\right)$ and phosphate buffer $\mathrm{pH} 7.4$ as receptor compartment $(15 \mathrm{ml})$ at $37 \pm 0.5^{\circ} \mathrm{C}$. The receptor compartment was filled and attractively mixed at $300 \mathrm{rpm}$ all through the investigation. About $2 \mathrm{ml}$ of tests (emulsion and nanoemulsion) were mounted on the epidermal surface of rodent skin. Tests were pulled back at $0.5,1,2,3,4,5,6,7$, and $8 \mathrm{~h}$. For each time interim, $1 \mathrm{ml}$ receptor arrangement was gathered and separated with a $0.45 \mu \mathrm{m}$ syringe and investigated by HPLC to the determinate amount of oxyresveratrol. To keep up sink conditions, fresh phosphate buffer was included in the receptor compartment in the meantime [10].
HPLC analysis

HPLC analysis was performed to examination oxyresveratrol in nanoemulsion and macroemulsion. The compound was utilized C18 fortified silica gel, $5 \mu \mathrm{m}, 150 \times 4.6 \mathrm{~mm}$ molecule measure, YMC section from Phenomenex (Torrance, USA). The indicator was ultraviolet (SPD$20 \mathrm{~A}$, Shimadzu, Japan) at $320 \mathrm{~nm}$. The mobile stage was acetonitrile and water containing $1 \%$ acetic acid $(25: 75 \mathrm{v} / \mathrm{v})$ and stream rate of $1 \mathrm{ml} / \mathrm{min}$ in isocratic mode. The infusion volume was $20 \mu \mathrm{l}$ and runtime of $15 \mathrm{~min}$. Oxyresveratrol stock arrangement $1 \mathrm{mg} / \mathrm{ml}$ in $80 \%$ ethanol was arranged and diluted into $0.0005,0.001,0.005,0.01$, and $0.05 \mathrm{mg} / \mathrm{ml}$ to make alignment bend. The two emulsions were diluted in $80 \%$ ethanol each [12].

\section{Data analysis}

The two emulsions were resolved the aggregate sum $\left(\mathrm{Q}, \mu \mathrm{g} / \mathrm{cm}^{2}\right)$ of oxyresveratrol penetrated through rodent skin. The flux $\left(\mathrm{J}, \mu \mathrm{g} / \mathrm{cm}^{2} / \mathrm{h}\right)$ of oxyresveratrol was gotten by plotting the total measure of penetrated per unit territory of skin versus time.

\section{RESULTS}

\section{Pseudoternary phase diagram}

Fig. 1 showed the pseudoternary phase diagram of VCO, Smix (mixture of surfactant and cosurfactant 1:1), and water. The obtained nanoemulsion area was present in the area passed by the yellow line. From the experimental results, nanoemulsion was formed by composition of VCO and surfactant mixture with ratio of 9:1 in all tested compositions (10-50\%). The amount of surfactant mixture that was less than that ratio is not sufficient to form nanoemulsion. Based on these preliminary results, the selected formula consisted of $2 \%$ VCO, $18 \%$ surfactant mixture, and $80 \%$ water phase and then was continued with evaluation and in vitro assay.

\section{Characterization of nanoemulsion}

The nanoemulsion was evaluated organoleptically and visual homogeneity and then was measured pH value. Fig. 2 and Table 1 show the organoleptic of nanoemulsion. Nanoemulsion of white mulberry root extract was a yellow-brown liquid, aromatic odor and

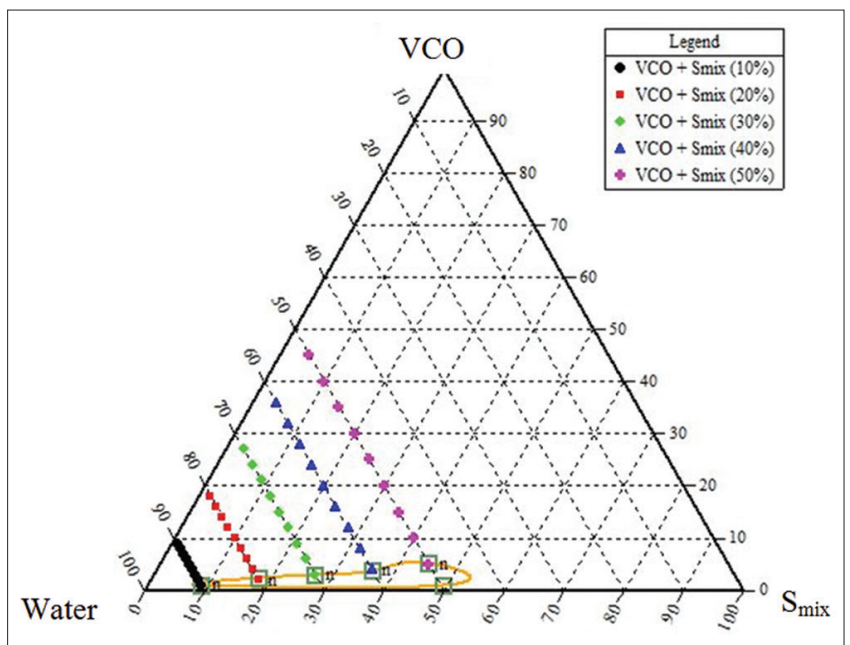

Fig. 1: Pseudoternary diagram of virgin coconut oil -water-Smix

Table 1: Organoleptic, $\mathrm{pH}$, and homogeneity of nanoemulsion

\begin{tabular}{ll}
\hline Organoleptic & Properties \\
\hline Color & Yellow-brown \\
Odor & Aromatic \\
Texture on skin & No sticky \\
Homogeneity & Homogeny \\
pH & 6.5 \\
\hline
\end{tabular}


had a non-sticky texture when applied to the skin. The yellow-brown color of nanoemulsion came from the added extract. Homogeneity was tested with object glass and showed the nanoemulsion distributed homogeneously. The $\mathrm{pH}$ value of the white mulberry root nanoemulsion was 6.5 and still within the range of skin $\mathrm{pH}(4.5-6.5)$.

The viscosity was determined by Ostwald viscometer and the result showed viscosity value of $4.03 \times 10^{-3}$ Pa.s. Table 2 shows that nanoemulsion had average globule size of $81.61 \mathrm{~nm}$ and a PDI value of 0.220 with a normal distribution curve as shown in Fig. 3. The small globule size appeared as clear or opaque liquid that is distinct from the milky white color associated with regular emulsions [13]. The zeta potential of white mulberry root extract nanoemulsion was $-1.56 \mathrm{mV}$.

\section{Stability test}

The result of the cycling test was showed in Table 3. There are no visible changes in nanoemulsions organoleptic, include color, odor, texture and homogeneity of nanoemulsion. After 6 cycles, there was a decrease in $\mathrm{pH}$ value of 0.49 (from 6.5 to 6.01). The $\mathrm{pH}$ changed that occurred was still acceptable within the $\mathrm{pH}$ range of the skin.

Physical stability tests were performed at three different temperatures; low temperature $\left(4^{\circ} \mathrm{C}\right)$, room temperature $\left(28^{\circ} \mathrm{C}\right)$, and oven temperature $\left(40^{\circ} \mathrm{C}\right)$ for 3 months ( 12 weeks). Observations of changes in nanoemulsion's organoleptic and $\mathrm{pH}$ measurements were carried out every 2 weeks. The 12 -week test results showed no change in odor organoleptic, texture when applied, and homogeneity of preparations at all three storage temperatures. No phase separation and creaming occurred. Changes that occurred were seen in the color of the nanoemulsion on which became darker at $40^{\circ} \mathrm{C}$ and became brighter at $4^{\circ} \mathrm{C}$ storage. The preparations which were stored at $28^{\circ} \mathrm{C}$ showed no color changed.

Changes in the $\mathrm{pH}$ of the preparations in the three storage temperatures are shown in Fig. 4. The pH measurement results for 12 weeks indicate a gradual decrease in each storage temperature, but still within acceptable limits the $\mathrm{pH}$ of the skin (4.5-6.5).

\section{In vitro skin penetration test}

The penetration test was performed to analyze the oxyresveratrol penetration ability from nanoemulsion and to compare with that regular emulsion. The nanoemulsion was prepared based on the previous formulation and method, wherein Tween 80, PEG 400, and VCO had a ratio of 9:9:2 while for regular emulsion was used Tween 80, PEG 400, and VCO in the ratio of 8:8:4 with both the same compositions of excipient. Both nanoemulsion and regular emulsions were made by homogenizing using a magnetic stirrer at a speed of $1250 \mathrm{rpm}$.

Fig. 5 shows the in vitro release profile of oxyresveratrol from nanoemulsion and from regular emulsion using phosphate buffer $\mathrm{pH} 7.4$ as receptor media. The results of the in vitro penetration test showed that the cumulative amount of penetrated oxyresveratrol from

Table 2: Globule size and polydispersity index

\begin{tabular}{ll}
\hline Z-average (nm) & Polydispersity index \\
\hline 81.61 & 0.220 \\
\hline
\end{tabular}

Table 3: Cycling test

\begin{tabular}{lll}
\hline Observation & Fresh condition & After $\mathbf{6}$ cycles \\
\hline Color & Brownish-yellow & Brownish-yellow \\
Texture on skin & No sticky & No sticky \\
Odor & Aromatic & Aromatic \\
Homogeneity & Homogeny & Homogeny \\
pH & 6.52 & 6.01 \\
\hline
\end{tabular}

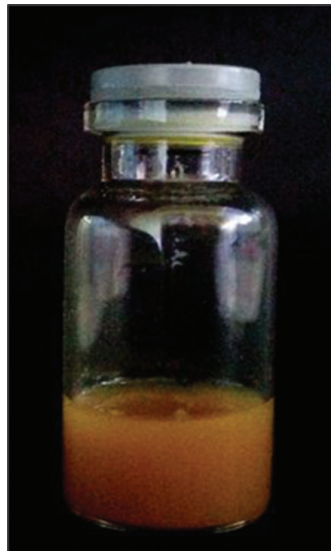

Fig. 2: Nanoemulsion of Morus alba root extract

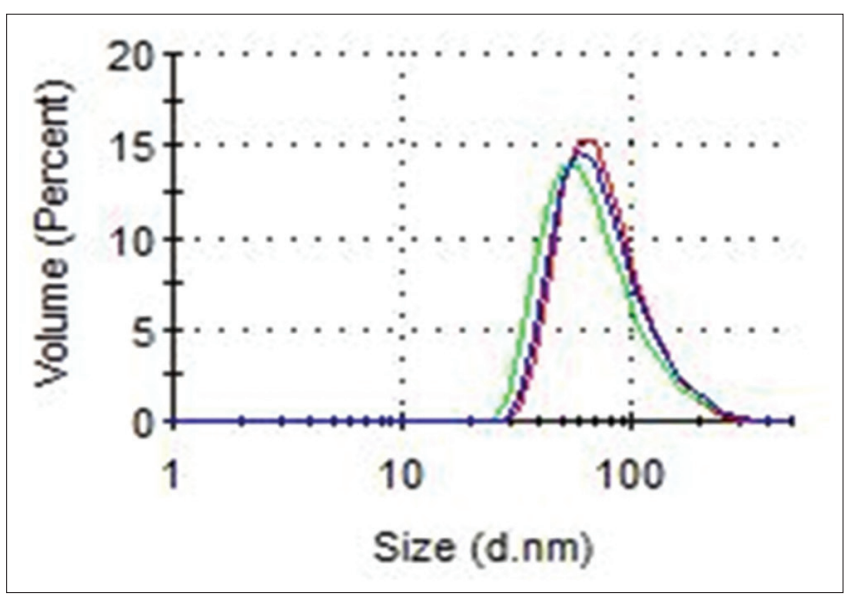

Fig. 3: Distribution of globule size

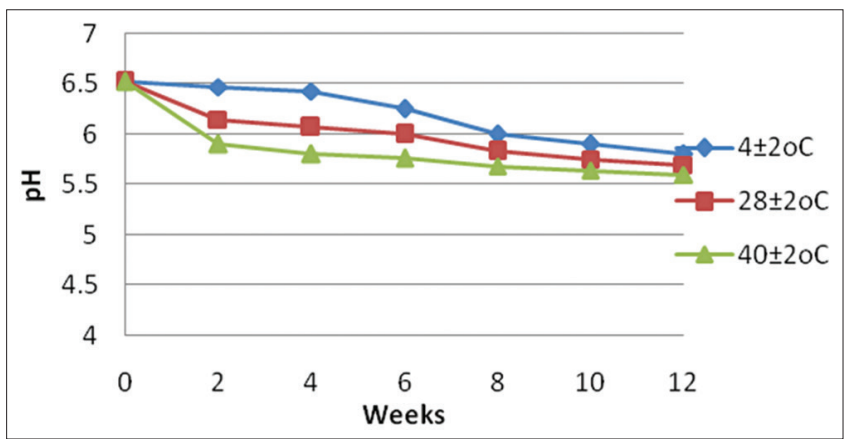

Fig. 4: PH of nanoemulsions for 12 weeks

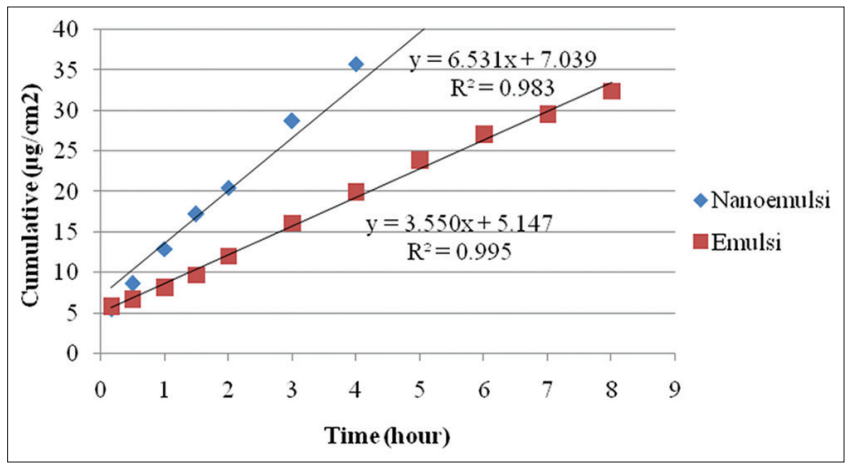

Fig. 5: Franz diffusion cell penetration test 
nanoemulsion was $55.86 \mu \mathrm{g} / \mathrm{cm}^{2}$ with a flux of $6.5316 \mu \mathrm{g} / \mathrm{cm}^{2} / \mathrm{h}$ and from a regular emulsion of $32.45 \mu \mathrm{g} / \mathrm{cm}^{2}$ with a flux of $3.5501 \mu \mathrm{g} / \mathrm{cm}^{2} / \mathrm{h}$. The percentage of oxyresveratrol penetrated from nanoemulsion on for $8 \mathrm{~h}$ was $25.44 \%$. These results indicate that nanoemulsion on increases the penetration ability of oxyresveratrol was 1.8 times better than regular emulsion.

\section{DISCUSSION}

Nanoemulsions are the most promising mode of drug delivery system that captured the attention of many pharmaceutical scientists due to its tiny nanosized droplets that are spherical and also exhibit good kinetic stability [14]. There are two methods to make nanoemulsion, low-energy and high-energy methods. Sari et al. (2018) have been successfully made nanoemulsion by spontaneous emulsification method (low energy) with 5\% red palm olein with $40 \%$ surfactant Tween 80 and $20 \%$ cosurfactant sorbitol [15] while another study suggests that the use of Ultra-Turrax (high energy) is a good strategy to prepare nanoemulsion [16].

The pseudoternary phase diagram is an auxiliary method for determining initial screening of surfactant and cosurfactant compositions for nanoemulsion on formulations. From the trial results, the nanoemulsion utilizing the least conceivable surfactant fixation while keeping up the strength and little globule estimate was picked as the following formulation. Research by He et al. (2017) showed that oxyresveratrol has a solubility of $168.90 \mathrm{mg} / \mathrm{mL}$ in Tween 80 and $445.37 \mathrm{mg} / \mathrm{mL}$ in PEG 400, so it becomes an option for use as a surfactant and cosurfactant [17].

The size or diameter of the globule of the nanoscale conductor system is the most important parameter since the entrance of a compound into the skin can happen through the pores of pilosebaceous $(10-70 \mu \mathrm{m})$, pores of sweat glands $(60-80 \mu \mathrm{m})$, and most often through the intercellular lipid matrix of stratum corneum (about $75 \mathrm{~nm}$ ) [18-20]. In addition, due to its small size, considerable increase in surface area causes increased contact with the skin and increases absorption [21].

According to McClements (2015), the general thickness of two stages, the scattered stage and the constant stage impact the consequences of the size decrease process. At the point, when the thickness is generally too high, globules end up impervious to break and rather start to pivot without anyone else hub when given erosion. The type of oil and oil volume also affect the size of globule. Nanoemulsion which made with high-viscosity oil has a larger globule size [22].

The consistency of the bead estimate dispersion is estimated as the PDI. The PDI is a file that portrays the size variety. The higher the PDI esteem, the more extensive the span of the disseminated bead [11]. The index value is in the range of values between 0 (uniform size distribution) and 0.5 (width size distribution). Nanoemulsion is called as "monodisperse" if the PDI is $<0.2$; while a much higher polydispersity $(>0.4)$ is indicated by ordinary emulsions. This PDI provides information about the physical stability of a dispersion system. The low PDI value indicates that the dispersion system that is formed is more stable for the long term [23].

The dispersed phase globules are known to acquire an electric charge during the process of emulsification. The globules gather to charge layers around themselves called Helmholtz double layer; zeta potential in which the difference in charge potentials between points on the fixed charge layer on the globule to the point where both positive and negative charge exist. Zeta potential can be measured by zeta meter and helps in the prediction of flocculation behavior of the system. Dispersed phase systems having a zeta potential value higher than $0.25 \mathrm{mV}$ are likely to be stable because the intensity of the charge on the particles repels them from one other [24].

As a standard guideline, the total estimation of zeta potential over $30 \mathrm{mV}$ give great stability or more $60 \mathrm{mV}$ give excellent stability $[25,26]$.
Research by Nurdianti et al. (2017), nanoemulsion on astaxanthin developed with sunflower oil composition, Kolliphor RH40, and PEG 400 (1:8:1) has a potential zeta value of $-5.38 \mathrm{mV}$ [27]. Compared with white mulberry root extract nanoemulsion, the two nanoemulsions have a potential zeta value which is close to 0 because it used a surfactant and non-ionic surfactant.

Numerous segments of nanoemulsion can influence the capacity to enter through the skin. The nearness of sebum in hair follicles, it is conceivable that oil-based nanoemulsion, surfactants, and alcohols may encourage transport of both the hydrophilic and lipophilic compound. Numerous excipients from nanoemulsion go about as entrance enhancers in topical applications. Due to the hydrophobic attributes of the skin, the oil period of nanoemulsion which additionally has hydrophobic properties can expand the entrance of dynamic fixings [28]. Surfactants are otherwise called skin infiltration enhancers since they can break up lipids in the stratum corneum as a noteworthy hindrance to the take-up of topical medications [29]. The infiltration of surfactant atoms into the lipid lamellae of the stratum corneum depends by and large on the solvency and surfactant segment [30]. Cosurfactant can likewise influence the conduct of medication transport on the skin. For instance, ethanol, it can increment lipophilic transport of the stratum corneum through the arrangement of pores in the stratum corneum [31,32]. What's more, hydrated skin is commonly progressively penetrable, with the goal that the water contained in nanoemulsion is additionally a perfect hydration enhancer [33].

\section{CONCLUSION}

Nanoemulsion of white mulberry root extract was made by composition of $2 \%$ VCO, $18 \%$ mixture of surfactants Tween 80 and PEG 400 (1:1), and $80 \%$ water. In vitro penetration tests showed the cumulative amount of penetrated oxyresveratrol from nanoemulsion on preparations $\left(55.86 \mu \mathrm{g} / \mathrm{cm}^{2}\right)$ was higher than that of regular emulsion $\left(32.45 \mu \mathrm{g} / \mathrm{cm}^{2}\right)$.

\section{ACKNOWLEDGMENTS}

This study was supported by DRPM UI grant of indexed international publication of student final project 2018.

\section{AUTHORS' CONTRIBUTIONS}

All authors certify that they have participated sufficiently in work to take public responsibility for the content, including participation in the concept, design, analysis, writing, or revision of the manuscript.

\section{CONFLICTS OF INTEREST}

There are no any conflicts of interest in this study.

\section{REFERENCES}

1. Chan EW, Lye PY, Wong SK. Phytochemistry, pharmacology, and clinical trials of Morus alba. Chin J Nat Med 2016;14:17-30.

2. Kim YM, Yun J, Lee CK, Lee H, Min KR, Kim Y, et al. Oxyresveratrol and hydroxystilbene compounds. Inhibitory effect on tyrosinase and mechanism of action. J Biol Chem 2002;277:16340-4.

3. Silva F, Figueiras A, Gallardo E, Nerín C, Domingues FC. Strategies to improve the solubility and stability of stilbene antioxidants: A comparative study between cyclodextrins and bile acids. Food Chem 2014;145:115-25.

4. Breuer MM. Cosmetics emulsions. In: Becher P, editor. Encyclopedia of Emulsions Technology. New York: Marcel Dekker; 1985.

5. Solans C, Izquerdo P, Nolla J, Azemar N, Garcia-Celma MJ. Nanoemulsions. Curr Opin Colloid Interface Sci 2005;10:102-10.

6. Calderó G, García-Celma MJ, Solans C. Formation of polymeric nano-emulsions by a low-energy method and their use for nanoparticle preparation. J Colloid Interface Sci 2011;353:406-11.

7. Mcclements DJ. Nanoemulsions versus microemulsions: Terminology, differences and similarities. Soft Matter 2012;8:1719-29.

8. Kabri TH, Arab-Tehrany E, Belhaj N, Linder M. Physico-chemical characterization of nano-emulsions in cosmetic matrix enriched on omega-3. J Nanobiotechnology 2011;9:41. 
9. Moghassemi S, HadjizadehA. Nano-niosomes as nanoscale drug delivery systems: An illustrated review. J Control Release 2014;185:22-36.

10. Zheng WW, Zhao L, Wei YM, Ye Y, Xiao SH. Preparation and the in vitro evaluation of nanoemulsion system for the transdermal delivery of granisetron hydrochloride. Chem Pharm Bull (Tokyo) 2010;58:1015-9.

11. Affandi MM, Juliantoa T, Majeed A. Development and stability evaluation of astaxanthin nanoemulsion on. Asian J Pharm Clin Res 2011;4:142-8.

12. Soonthornsit N, Pitaksutheepong C, Hemstapat W, Utaisincharoen P, Pitaksuteepong T. In vitro anti-inflammatory activity of Morus alba L. Stem extract in LPS-stimulated RAW 264.7 cells. Evid Based Complement Alternat Med 2017;2017:3928956.

13. Perrie Y. Pharmaceutical nanotechnology and nanomedicine. In: Aulton ME, Taylor KM, editors. Aulton's Pharmaceutics: The Design and Manufacture of Medicines. London: ChurcillLivingstone, 2013. p. 777-96.

14. Nirmalaa MJ, Shivashankarb M, Mukherjeea A, Chandrasekaran N. Fluconazole: A simple nanoemulsion drug delivery system. Int J Pharm Pharm Sci 2013;5:716-7.

15. Sari F, Sinaga KR, Siahaan D. Formulation and evaluation of red palm olein nanoemulsion. Asian J Pharm Clin Res 2018;11:237-40.

16. Giongo JL, Vaucher RD, Ourique AF,Steffler MC, Frizzo CP, Hennemman B, et al. Development of nanoemulsion containing Pelargonium graveolens oil: Characterization and stability study. Int $\mathbf{J}$ Pharm Pharm Sci 2016;8:271-6.

17. He J, Zhu Q, Dong X, Pan H, Chen J, Zheng ZP, et al. Oxyresveratrol and ascorbic acid $\mathrm{O} / \mathrm{W}$ microemulsion: Preparation, characterization, anti-isomerization and potential application as antibrowning agent on fresh-cut lotus root slices. Food Chem 2017;214:269-76.

18. Baroli B, Ennas MG, Loffredo F, Isola M, Pinna R, López-Quintela MA, et al. Penetration of metallic nanoparticles in human full-thickness skin. J Invest Dermatol 2007;127:1701-12.

19. Lauer AC, Ramachandran C, Lieb LM, Niemiec S, Weiner ND. Targeted delivery to the pilosebaceous unit via liposomes. Adv Drug Deliv Rev 1996;18:311-24.

20. Johnson ME, Blankschtein D, Langer R. Evaluation of solute permeation through the stratum corneum: Lateral bilayer diffusion as the primary transport mechanism. J Pharm Sci 1997;86:1162-72.

21. Goddeeris C, Cuppo F, Reynaers H, Bouwman WG, Van den Mooter G. Light scattering measurements on microemulsions: Estimation of droplet sizes. Int J Pharm 2006;312:187-95.

22. McClements DJ. Food Emulsions: Principles, Practices, and Techniques. Boca Raton: CRC press; 2015.

23. Nastiti CMRR, Ponto T, Abd E, Grice JE, Benson HAE, Roberts MS, et al. Topical nano and microemulsions for skin delivery. Pharmaceutics 2017;9:E37

24. Madaan V, Chanana A, Kataria MK, Bilandi A. Emulsion technology and recent trends in emulsion applications. Int Res J Pharm 2014;5:533-42.

25. Wissing SA, Kayser O, Müller RH. Solid lipid nanoparticles for parenteral drug delivery. Adv Drug Deliv Rev 2004;56:1257-72.

26. Jacobs C, Kayser O, Müller RH. Nanosuspensions as a new approach for the formulation for the poorly soluble drug tarazepide. Int J Pharm 2000;196:161-4

27. Nurdianti L, Aryani R, Indra I. Formulasi dan karakterisasi SNE (Self Nanoemulsion) astaxanthin dari Haematococcus pluvialis sebagai super antioksidan alami. J Sains Farmasi Klinis 2017;4:30-6.

28. Hoeller S, Sperger A, Valenta C. Lecithin based nanoemulsions: A comparative study of the influence of non-ionic surfactants and the cationic phytosphingosine on physicochemical behaviour and skin permeation. Int J Pharm 2009;370:181-6.

29. Potts RO, Mak VH, Guy RH. Strategies to enhance permeability via stratum corneum lipid pathways. Adv Lipid Res 2016;24:173-210.

30. Som I, Bhatia K, Yasir M. Status of surfactants as penetration enhancers in transdermal drug delivery. J Pharm Bioallied Sci 2012;4:2-9.

31. Ghanem AH, Mahmoud H, Rohr UD, Borsadia S, Liu P, Fox JL, et al. The effects of ethanol on the transport of $\beta$-estradiol and other permeants in hairless mouse skin. II. A new quantitative approach. J Control Release 1987;6:75-83.

32. Lane ME. Skin penetration enhancers. Int J Pharm 2013;447:12-21.

33. Gupta RR, Jain SK, Varshney M. AOT water-in-oil microemulsions as a penetration enhancer in transdermal drug delivery of 5-fluorouracil. Colloids Surf B Biointerfaces 2005; 41:25-32. 